\title{
Planejamento e Organização \\ Territorial do Turismo
}

Doris v. d. M. Ruschmann *

RESUMO: Apresenta-se o planejamento turístico como atividade fundarnental para o desenvolvónento equilibrado de regiöes receptoras do turisno e em harmonia com os seus recursos fisicos, culsurais e sociais. Abordam-se os principais enfoques do planejamento tur'stico, as fases do processo e a importancia da hierarquização dos recursos naturais, visando o seu aproveitamento adequado e, principabmente, a sua preservação.

UNITERMOS: Turismo: planejamento, recursos.

ABSTRACT: Touristic planning is presented as a fundamental activity for the balanced development of receptive tourist regions and in harmony with their physical, cultural and social resources.

We approached the main focalization of the planning of tourism, the phases of the process and the omportance of the hierarchization of the natural resources, having in view their adequate utilization and specially, their preservation.

KEY WORDS: Tourism: planning, resources.

\section{INTRODUÇÃO}

O planejamento da atividade turística constitui uma tarefa bastante complexa, pois envolve aspectos relativos à ocupação territorial, à economia, sociologia e cultura dos núcleos receptores, bem como as características dos locais emissores e a conseqüente heterogeneidade dos turistas.

O planejamento dos espaços com potencial turístico é tarefa do Estado que, para desenvolvê-los, se vê diante de dois objetivos conflitantes: o primeiro, que $\epsilon$ o de prover a oportunidade e o acesso a

(*) Professora Assistente (Mestre) do Curso de Turismo da ECA/USP. Professora e As sessora de Pesquisas no Curso Superior de Hotelaria do CEATEL/SENAC Rua Água de Figueira, 52 - 04923 - São Paulo - SP - Brasi 
estes locais para o maior número de pessoas possível, se contrapōe ao segundo, relacionado com aquele de proteger e evitar a descaracterização dos locais privilegiados pela natureza e a cultura original da população receptora Por $1 s s o$, o planejamento das facilidades e equipamentos a implantar nos espaços naturais requer nāo apenas estudos que avaliem todos os aspectos da demanda atual e futura, como também o estabelecimento de parâmetros de ocupação, baseados na determinação dos limites da capacidade de utilização desses espaços e dos recursos.

A metodologia para o desenvolvimento dos recursos turísticos é complexa, e há inúmeras opçōes; porém os objetivos e as prioridades desse desenvolvimento são altamente influenciados por critérios políticos, sociais e econômicos. Um dos maiores problemas dos planos de desenvolvimento turístico reside na sua falta de integração aos outros programas sociais, econômicos e físicos das naçōes. Por esta razão, tais programas acabam sendo empreendidos isoladamente.

O planejamento da atividade turística deve, necessariamente, estar inserido em sua política nacional de desenvolvimento, devido às suas influências econômicas, sociais e culturais.

\section{ENFOQUES DO PLANEJAMENTO TURÍSTICO}

Historicamente, os estudos relativos ao planejamento turístico têm se concentrado tanto no levantamento jos aspectos físicos quanto nas considerações econômicas do enômeno, mas sempre com enfoques parci»1s, como os destacados nos itens 2 . is a 2.5

\subsection{Enfoque Urbanístico}

Fundamenta-se em uma análise e avaliação detalhada dos recursos turísticos, geralmente os físicos, existentes no país ou região objeto de estudo. Com base na qualidade e nas possibilidades de exploração, culmina na elaboração de um plano de desenvolvimento denominado PLANO DIRETOR, relacionado com o aproveitamento e o uso do solo.

\subsection{Enfoque da Política Econômica}

Baseia-se no emprego de metodologia e técnicas utilizadas expe- rimentadas em outros campos da atividade econômica, adaptando-as ao caso específico do turismo.

\subsection{Enfoque Pasolf ("Products; Analysis Sequence for Outdo- or Leisure Planning”')}

Baseia-se no conceito do "produto turístico", e considera todos os fatores que, em um determinado momento, podem afetar o desenvolvimento da infra-estrutura, as instalaçōes e o funcionamento da atividade.

\subsection{Modelos de Simulaçāo}

Referem-se a modelos empregados para realizar estudos relativos às atividades recreativas ao ar livre e para o planejamento do turismo a nível nacional. Têm sua importância para verificação das conseqüências da atividade no ordenamento físico do território em zonas especialmente afetadas.

\subsection{Planejamento Estratégico}

Proposto por Acerenza', enfoca o planejamento turístico do ponto de vista administrativo e o deñne como sendo "o processo destinado a determinar os objetivos gerais do desenvolvimento, as políticas $e$ as esirategias que guiarão os aspectos relativos aos investimentos o uso e o orçenamento dos recursos utilizáveis para este fim”".

\subsection{Visāo Integrada}

Independentemente dos diversos enfoques do planejamento turístico utilizado nos diferentes países e em fases distintas do seu desenvolvimento, ressalta-se a necessidade de o processo ocorrer de forma integrada, e de que deve ter por objetivo o desenvolvimento coerente dos elementos físicos, econômicos, sociais, culturais, técnicos e ambientais, visando a satisfação dos turistas e dos empreendedores, além da preservação do meio ambiente. 


\section{PLANEJAMENTO INTEGRAdO DO}

\section{DESENVOLVIMENTO TURISTICO}

O planejamento integrado do desenvolvimento turístico vem sendo proposto por diversos autores europeus e americanos tanto do norte como do sul. No Brasil, recentemente Beni, em sua tese de doutoramento ${ }^{2}$, propôs o SISTUR - Sistema de Turismo, baseando-se na teoria dos Sistemas. Conceitua-o como sendo "o conjunto de procedimentos e doutrinas, idéias ou princípios, logicamente ordenados e coesos, com a intenção de descrever o funcionamento da atividade turística como um todo". O autor situa o turismo em toda a sua abrangência, complexidade e multicausalidade em um esquema sintetizador dinâmico, que demonstra as combinaçōes multifacetadas de forças e energias.

O modelo teórico referencial proposto sugere a análise e o estudo da integraçāo dos seguintes conjuntos:

a) relaçōes ambientais que envolvem os seguintes sub-sistemas: ecológico, social, económico e cultural;

b) organizaçăo estrutural que envolve a superestrutura e a infra-estrutura;

c) açōes operacionais que envolvem, no mercado, a oferta e a demanda relacionadas à produção e ao consumo respectivamente; dependem, ambos, do sistema de distribuição.

Para que o levantamento de dados, que fundamenta um processo de planejamento turístico, possa ser realizado adequadariente é preciso que se tenha uma visão tão abrangente quanto possível e em grande profundidade do fato e do fenómeno turístico.

Assim, faz-se necessário elencar e fazer uma descrição exaustiva dos elementos que constituem as realizaçōes do SISTUR com todos os componentes que estão a ele ligados por relaçóes de interdependência.

A responsabilidade do planejamento turístico integrado, que considera todos os aspectos e fatores intervenientes da atividade, $e$ responsabilidade do Organismo Estatal específico que, por sua origem, dispōe de mais recursos financeiros e técnicos. Entretanto, devido ao caráter interdisciplinar e convergente da atividade, a base técnica deverá ser bastante diversificada, e, em casos concretos, este órgão deverá recorrer à participaçāo ou assessoria de especialistas que participarăo da equipe planejadora - como propóe Baretje ${ }^{3}$, em seu esquema metodológico para o planejamento de regióes turísticas (Figura 1, p. 70).

Este esquema destaca quatro áreas que deverāo ser levantadas de forma detalhada, na regiāo cujo potencial turístico se pretenda 66 desenvolver adequadamente Baretje especifica todas as atividades relacionadas ao levantamento de dados, os conseqüentes relatórios e os entrelaçamentos das seguintes áreas

a) meio ambiente.

b) população.

c) economia

d) quadro institucional

Na parte superior de cada um dos quadros que correspondem às etapas do processo, há a indicação dos profissionais especializados que deverão compor a equipe de trabalho e que atuarāo, de acordo com a especificidade da etapa, em conjunto ou isoladamente, seja analisando os dados, seja redigindo os relatórios intermediários e relatório final (PLANO DIRETOR), bem como o estudo crítico do mesmo.

Um planejamento turístico que se pretenda viável deverá, necessariamente. contar com a equipe técnica sugerida, e julga-se ser este um modelo a ser seguido, na viabilização do desenvolvimento adequado de processos de planejamento e a conseqüente implantação do plano a ser proposto pela equipe.

\section{PLANEJAMENTO E ORgANizAÇĀO TERRITORIAL DO TURISMO}

A finalidade do planejamento físico do turismo consiste no ordenamento das açōes do homem sobre o território, e ocupa-se em direcionar a construção de equipamento e facilidades de forma adequada, evitando, desta forma, os efeitos negativos da exploração dos recursos naturais

O espaço turístico natural, segunco Boullon ${ }^{4}$, é conseqüência da presença e da dis ribuição territorial das atraçōes turísticas - a matéria-prima do turismo

Uma das características físicas das atraçōes turísticas reside na sua descontinuidade territorial, pois mesmo que estejam próximas, e pouquíssimas vezes agrupadas, na maioria dos países que possuem uma grande quantidade de atraçōes naturais, notam-se grandes áreas do território que não apresentam nenhum atrativo.

Por isso, o critério de regionalização das atrações se torna praticamente inviável. Boullon añma que a melhor forma de determinar o espaço turístico consiste em observar a distribuição territorial das atraçōes, a fim de detectar os agrupamentos ou as concentraçōes mais marcantes

No que se refere especificamente aos recursos naturais, fazern-se distinçōes entre aqueles que devem ser preservados e aque- 
les que poderăo ser desenvolvidos para o turismo, porém com diferentes graduaçóes de prioridades ou de intensidade.

Baud-Bovy e Lawson ${ }^{5}$ sugerem o critério baseado nos itens descritos a seguir.

a) Recursos Ṕrotegidos - Sáo áreas com restriçbes de acesso, total ou parcial, desprovidas; ou com algumas facilidades turísticas.

Exemplo: parques nacionais, áreas naturais de interesse cient/fico ou de beleza extraordinária, sítios de valor anqueológico. Neste caso, os objetivos conservacionistas devem prevalescer diante dos turísticos.

b) Recursos prioritarios para o desenvolvimento turtstico - São áreas de grande importância para o turismo, nas quais $E$, ou poderá ser, a atividade principal. Uma série de facilidades deverá ser implantada com este objetivo.

c) Recursos de grande interesse turístico - Săo áreas nas quais o turismo poderá se desenvolver paralelamente a outras atividades económicas. Deverăo ser providas de algumas facilidades que, entretanto, poderão ser poucas e dispersas.

d) Recursos de interesse turístico secundário - São áreas nas quais a dimensāo do turismo dependerá das oportunidades proporcionadas pelo desenvolvimento de outras atividades econômicas ou poderá ser retardado, tendo um controle ambiental limitado.

Para os recursos passiveis de aproveitamento turistico, recomenda-se uma avaliaçāo, ou seja, uma análise crítica das atrações, a fim de estabelecer seu interesse turístico sobre bases objetivas e comparáveis entre si, assinalando sua correspondência hierárquica ${ }^{6}$ que pode se situar nos níveis citados a seguir

a) Hierarquia 3 - Atração excepcional, é altamente significativa para o mercado turístico internacional: capaz de, por si s 6 , motivar uma importante corrente de turistas.

b) Hierarquia 2 - Atração com aspectos excepcionais em um país, capaz de motivar uma corrente de turistas nacionais ou estrangeiros, seja por si só, ou em conjunto com outras atraçōes.

c) Hierarquia 1 - Atração com alguns aspectos chamativ interessar os turistas que vieram de longe para a regiâo, por outras motivaçóes turísticas, ou capaz de motivar correntes turísticas locais.

d) Hierarquịa $O$ - Atração sem méritos suficientes para ser inclurda nas híerarquias anteriores, que, porem, faz parte do parrimbnio turístico como elemento que pode completar outros de maior interesse, no desenvolvimento de complexos turísticos.

A tarefa de inventariar recursos turísticos físicos, apesar de complexa, tem a vantagem de que o pesquisador trabalha com um 68
Indicador praticamente invariável, que são as atrações naturais

Estas, a menos que ocorram catástrofes, tais como terremotos, deslizamentos de terra, grandes inundações ou secas, dificilmente mudam seu conteúdo ou atratividade, Exemplo: grutas, cavernas, cachoeiras, lagos, baías, rochedos etc.

Apesar disso, não é possível negligenciar a sua avaliação correta, sob o risco de valorizar uma pertencente a uma hierarquia meno e relegando aquela de hierarquia superior a um plano inferior.

De acordo com as circunstâncias, poder-se-á atribuir valores para cada uma das hierarquias, para, no caso de regiōes que possuem diversos tipos de atraçōes, poder-se estabelecer seu valor diante de outras, que também dispõem de um número variado de recursos turísticos.

\section{CONCLUSĀO}

Na maioria dos casos, a grande motivação das viagens turísticas se refere aos aspectos ambientais. As pessoas viajam para determinadas destinações devido ao seu clima, à beleza das suas paisagens, ou para apreciar as construçōes feitas pelo homem.

Entretanto, o afluxo descontrolado de turistas poderá descaracterizar completa e, muitas vezes, definitivamente as atraçōes que motivaram a visita.

Por isso, o planejamento se apresenta como o fundamento para o desenvolvimento turístico equilibrado e em harmonia com os recursos físicos, culturais e sociais das regiōes receptoras, evitando, assim, que o turismo destrua as bases que o fazem existir.

\section{REFERÊNCIAS BIBLIOGRÁFICAS}

1. ACERENZA, Miguel A Administración del turimo: planificación y dirección. México: Trillas, 1985, p. 65 .

2. BENI, Mário C. Sistema de turismo: Construção de um modelo teórico referencial para a aplicação da pesquisa em turismo. São Paulo: ECAiUSP. 1987 (Tese de Doutorado)

3. BARETJE, Renné. Esquema metodológico para o planejamento de regiōes turlsticas. Tradução e apresentação de Doris V.D.M. Ruschmann e Sarah S. Bacal. In: I FÓ RUM NACIONAL DE TURISMO E LAZER, São Paulo: CRP/ECA/USP, Set./1980.

4. BOULLON, Rober to C. Planificación del espacio turtstico. México: Trillas, 1985, p. 65

5. BAUD-BOVY, Manuel \& LAWSON. Fred. Tourism and recreation development. Lon don: The Architectural Press, 1977 p. 164

6. CURSO DE PLANEJAMENTO DO DESENVOLVIMENTO TURISTICO Rio de Janeiro: Embratur/Cicotur. 1977 (Apostila 
